\title{
An Insight into the Sialomes of Bloodsucking Heteroptera
}

\author{
José M. C. Ribeiro, Teresa C. Assumpção, and Ivo M. B. Francischetti \\ Laboratory of Malaria and Vector Research, National Institute of Allergy and Infectious Diseases, \\ National Institutes of Health, Bethesda, MD 20892, USA \\ Correspondence should be addressed to José M. C. Ribeiro, jribeiro@niaid.nih.gov
}

Received 27 January 2012; Accepted 17 April 2012

Academic Editor: Mark M. Feldlaufer

Copyright ( $\odot 2012$ José M. C. Ribeiro et al. This is an open access article distributed under the Creative Commons Attribution License, which permits unrestricted use, distribution, and reproduction in any medium, provided the original work is properly cited.

\begin{abstract}
Saliva of bloodsucking arthropods contains dozens or hundreds of proteins that affect their hosts' mechanisms against blood loss (hemostasis) and inflammation. Because acquisition of the hematophagous habit evolved independently in several arthropod orders and at least twice within the true bugs, there is a convergent evolutionary scenario that creates a different salivary potion for each organism evolving independently to hematophagy. Additionally, the immune pressure posed by their hosts creates additional evolutionary pressure on the genes coding for salivary proteins, including gene obsolescence, which opens the niche for coopting new genes (exaptation). In the past 10 years, several salivary transcriptomes from bloodsucking Heteroptera and one from a seedfeeding Pentatomorpha were produced, allowing insight into the salivary potion of these organisms and the evolutionary pathway to the blood-feeding mode.
\end{abstract}

\section{Introduction}

The order Hemiptera (bugs) comprises hemimetabolous insects having in common tubular mouthparts specialized for sucking liquid diets. The diet of Hemiptera is varied, the majority feeding on plants by either tapping the vessels conducting sap or by lacerating and flushing tissues such as leaves or seeds. Within the suborder Heteroptera (true bugs), predatory feeding (with killing of the victim) also occurs, mostly targeting other insects but also including small vertebrates such as giant water bugs and toad bugs, as well as blood or hemolymph feeding (without killing the victim) from vertebrate and invertebrate animals. The mouthparts are not only important for channeling the liquid meal but are extremely important mechanically in finding the proper spot for meal suction [1].

Saliva is produced, sometimes copiously, during the probing phase (the time between mouthpart contact with the food substrate and the commencement of the meal) and throughout the meal $[31,32]$. This saliva is ejected at the tip of the maxillae by the salivary channel, which is built in between the interdigitations of the two plates that form the maxillae [33]. Saliva helps probing and feeding physically by liquefying insoluble or viscous tissues or by helping to seal the feeding site in sap suckers, were the phloem is under very high pressure [34]. Saliva has a biochemical role in aiding digestion of the meal, just as we have amylase in our own saliva; most remarkably, predacious bugs inject a highly hydrolytic cocktail into their victims that is digested while the prey is held by the predator, which can then later suck the liquefied victim and discard it as an empty shell. Saliva can also work pharmacologically by preventing the hosts' defense mechanisms against tissue loss, as occurs with the saliva of blood-feeding insects in preventing blood clotting, for example [35].

Among the Heteroptera, the blood-feeding habit evolved at least twice in the Cimicomorpha families, once in the Cimicidae (containing the bed bug) including the small sister group Polyctenidae (bat bugs), and in the Reduviidae (kissing bugs) from possible predacious or hemolymphsucking ancestors [1]. Within the Reduviidae, it is possible that the genus Rhodnius (tribe Rhodnini) is monophyletic, having evolved independently of the remaining triatomines (tribe Triatomini) [47-49]. The ancestral Cimicomorpha dates back to the Triassic/Jurassic border, over 250 MYA [1]; accordingly, the habit of blood or hemolymph feeding started 
in this group well before mammals irradiated. Within these hematophagous bugs, blood is the only diet for all immature and adult stages.

To obtain blood in a fluid state, these bugs have to counteract their host's hemostasis, the physiologic process that prevents blood loss, which includes the triad of platelet aggregation, blood clotting, and vasoconstriction. Bloodcirculating platelets may be triggered to aggregate by various signals, including ADP from broken cells and also released by activated platelets, collagen from subendothelial surfaces, thrombin (produced during blood clotting), and thromboxane $\mathrm{A}_{2}$ ( $\mathrm{TXA}_{2}$ - produced by activated platelets). Blood clotting may be initiated by activation of the intrinsic pathway via activation of Factor XII or by activation of the tissue factor pathway, both converging to the activation of Factor $X$ to $X_{a}$, which activates prothrombin to thrombin which in turn cleaves fibrinogen into fibrin, forming the blood clot. Activated platelets produce the vasoconstrictor $\mathrm{TXA}_{2}$ and also release stored serotonin and epinephrine, both powerful vasoconstrictors. A single magic bullet cannot properly destroy a redundant and complex obstacle such as this; rather, a magic potion of several antagonists is required.

Saliva of hematophagous arthropods also contains activities that interfere with the host's immune and inflammatory system in the form of immunomodulatory substances, particularly in ticks, which stay attached to their hosts for days or weeks, in contrast to minutes of host contact by bloodsucking bugs. Saliva also contains antimicrobial compounds that might help to control bacterial growth in the meal, because ejected saliva is reingested with the blood meal during blood feeding. For more detailed reviews on host hemostasis and immunity, see Francischetti et al. [56, 57].

Salivary anticlotting compounds from bloodsucking insects have been known to occur for nearly 100 years [58], while antiplatelet activity was first detected in the 1980s $[59,60]$ and vasodilators have only been described since the early 1990s [61]. In blood-feeding bugs, anticlotting agents from the saliva and crop of Rhodnius were described first by Hellman and Hawkins in 1965 [62], the first antiplatelet activity was reported in 1981 [59, 63], and Rhodnius salivary vasodilator was reported in 1990 [64]. Anticomplement activities have also been found [65], as well as antihistamine, antiserotonin [66], and antithromboxane [67] activities from Rhodnius saliva. An anesthetic was found in Triatoma infestans saliva in 1999 [68]. None of these earlier reports characterized the molecular nature of the compounds, most of these have been achieved in the past 20 years during the so-called "grind and find" period of discovery. Table 1 lists the molecularly characterized salivary components of bloodfeeding Hemiptera.

\section{On Sialomes}

In the past 10 years, a new method to unveil the salivary potion of hematophagous insects has been practiced in the form of decoding their sialotranscriptomes (from the Greek, sialo $=$ saliva , achieved by random sequencing of 500-2,000 cDNA clones originating from polyA-enriched RNA from the salivary glands of these animals. After assembly of these sequences into contigs (which represent full or near fulllength mRNA), these can be compared by bioinformatic tools such as BLAST and rpsblast [69] to other proteins in public databases (such as Swissprot, Gene Ontology [70], and GenBank [71] protein data banks, and CDD, PFAM, SMART and KOG [72], which are motif databases to be explored with the rpsblast tool) to identify closely related sequences and functional motifs. Additional searches for signal sequences indicative of secretion [73], for transmembrane helices [74], and for glycosylation sites [75] are also helpful to attempt functional classification of the protein. We are now on the eve of another revolution, with the increase by thousands of fold on the number of sequences that can be economically sequenced from these libraries, which will allow identification of the lesser expressed (and possibly most potent) proteins.

So far, 12 sialotranscriptomes-all done with less than 3,000 sequenced clones per organism-have been reported from Heteroptera, 11 of which are from blood-feeding Cimicomorpha and one from the seed-feeding Oncopeltus fasciatus. Oncopeltus belongs to the Pentatomomorpha, the closest group to Cimicomorpha [76] (Table 2). Among the Cimicomorpha sialotranscriptomes, only one derives from Cimicidae (the bed bug Cimex lectularius); the remaining are from Triatominae, encompassing four genera (Rhodnius, Triatoma, Dipetalogaster, and Panstrongylus), although some of these transcriptomes have no proteins deposited in public databases and too few expressed sequence tags (ESTs) publicly available. A few isolated protein sequences are also available from GenBank, deriving mostly from predatory bugs. The publicly available proteins are displayed together in Additional File 1, which is a hyperlinked Excel spreadsheet where the putative secreted proteins are organized in one worksheet and the putative housekeeping proteins are displayed in another worksheet.

The secreted proteins can be classified in two major groups, those belonging to ubiquitous protein families and those of unique status among the Hemiptera family, genus, or even species level (Table 3). We will proceed to describe the protein families in the order shown on Table 3.

\section{Ubiquitous Protein Families}

\subsection{Enzymes}

3.1.1. Apyrase, 5'-Nucleotidase, and NUDIX Hydrolase. Apyrases are enzymes that can hydrolyze ATP and ADP to AMP [77-79]. Initially the existence of true apyrases was doubted, because they could originate from a mixture of enzymes such as adenylate kinase and ATPases; however, their real intracellular existence in the potato was shown later $[79,80]$ and its function in carbohydrate anabolism and in the promotion of glycosyltransferases was only much later discovered, as indicated [81, 82]. The role of extracellular apyrases on preventing platelet aggregation was demonstrated for the first time in Rhodnius saliva [63, 83, 84] and later shown in the saliva of mosquitoes [85-87] and in the vascular endothelium [88-90]. The activity from Cimex lectularius was purified and cloned, revealing a new type of 
TABLE 1: Molecularly and functionally characterized salivary components of bloodfeeding Hemiptera.

\begin{tabular}{|c|c|c|c|c|c|}
\hline Name & Family & Insect & Activity & Notes & Reference \\
\hline Prolixin & Nitrophorin & Rhodnius prolixus & Anticlotting & FXa inhibitor & {$[2]$} \\
\hline RPAI & Lipocalin & R. prolixus & Antiplatelet & Binds ADP & {$[3,4]$} \\
\hline Nitrophorins & Nitrophorin & R. prolixus & Antihistamine & $\begin{array}{l}\text { Binds histamine, carrier } \\
\text { of } \mathrm{NO}\end{array}$ & {$[5,6]$} \\
\hline BABP & Nitrophorin & R. prolixus & Antiserotonin & Binds serotonin & [7] \\
\hline Inositol phosphatase & Inositol phosphatase & R. prolixus & Inositol phosphatase & Unknown function & [8] \\
\hline Lysophosphatidylcholine & Lipid & R. prolixus & Antihemostatic & & [9] \\
\hline $\mathrm{NO}$ & Inorganic gas & $\begin{array}{l}\text { R. prolixus, Cimex } \\
\text { lectularius }\end{array}$ & $\begin{array}{l}\text { Vasodilatory, } \\
\text { antiplatelet }\end{array}$ & Activates guanylate cyclase & {$[10,11]$} \\
\hline Apyrase & $5^{\prime}$-nucleotidase & Triatoma infestans & Antiplatelet & Destroys ADP & {$[12,13]$} \\
\hline Triplatin & Lipocalin & T. infestans & $\begin{array}{l}\text { Antiplatelet, } \\
\text { vasodilator }\end{array}$ & $\mathrm{TXA}_{2}$ binder & {$[14,15]$} \\
\hline Triafestin & Lipocalin & T. infestans & Anticlotting, antipain & Inhibits FXII activation & {$[16]$} \\
\hline Trialysin & Trialysin & T. infestans & Antimicrobial & Pore forming & {$[17,18]$} \\
\hline Pallidipin & Lipocalin & T. pallidipennis & Antiplatelet & $\begin{array}{c}\text { Collagen inhibitor } \\
\text { (possible } \mathrm{TXA}_{2} \text { binder) }\end{array}$ & {$[19,20]$} \\
\hline Triabin & Lipocalin & T. pallidipennis & Anticlotting & Anti-thrombin & {$[21-23]$} \\
\hline Procalin & Lipocalin & T. protracta & Allergen & Function unknown & {$[24]$} \\
\hline Dipetalodipin & Lipocalin & Dipetalogaster maxima & $\begin{array}{l}\text { Antiplatelet, } \\
\text { vasodilator }\end{array}$ & $\mathrm{TXA}_{2}$ binder & {$[25]$} \\
\hline Apyrase & Cimex apyrase & Cimex lectularius & Antiplatelet & Destroys ADP & {$[26]$} \\
\hline Nitrophorin & Inositol phosphatase & C. lectularius & $\begin{array}{l}\text { Antiplatelet, } \\
\text { vasodilator }\end{array}$ & Carrier of NO & {$[27-29]$} \\
\hline Fibrinolytic enzyme & Serine proteinase & Panstrongylus megistus & Anticlotting & & {$[30]$} \\
\hline
\end{tabular}

TABLE 2: Salivary transcriptomes of Hemiptera/Heteroptera.

\begin{tabular}{|c|c|c|c|}
\hline Organism & Number of ESTs on DBEST & Number of derived proteins in GenBank & Reference \\
\hline Rhodnius prolixus & 1,439 & 56 & {$[36]$} \\
\hline R. brethesi & 55 & 0 & {$[37]$} \\
\hline R. robustus & 121 & 0 & {$[37]$} \\
\hline Triatoma infestans & 1,738 & 167 & {$[38]$} \\
\hline Triatoma brasiliensis & 2,109 & 28 & {$[39]$} \\
\hline Triatoma matogrossensis & 2,230 & 196 & {$[40]$} \\
\hline Triatoma rubida & 1,850 & 93 & {$[41]$} \\
\hline Triatoma dimidiata & 53 & 53 & {$[42]$} \\
\hline Dipetalogaster maxima & 2,671 & 66 & {$[43]$} \\
\hline Panstrongylus megistus & 45 & 0 & {$[44]$} \\
\hline Cimex lectularius & 1,969 & 102 & {$[45]$} \\
\hline Oncopeltus fasciatus & 1,115 & 37 & [46] \\
\hline
\end{tabular}

enzyme that is ubiquitous in nature $[26,91,92]$. That for T. infestans, though, was found to belong to a completely different family, that of the $5^{\prime}$-nucleotidase family of enzymes [12]. Interestingly, sand flies [93] express salivary apyrases of the Cimex type, while mosquito salivary apyrases belong to the $5^{\prime}$-nucleotidase family $[87,94]$, clear examples of convergent evolution.

Nudix hydrolases or bis ( $5^{\prime}$-nucleosidyl)-tetraphosphatases (EC: 3.6.1.17) are enzymes that hydrolyze nucleotides joined by their phosphate groups such as AP4A or AP5A in the case of diadenosine nucleotides, which are known agonists of platelet aggregation and inflammation [95-98]. C. lectularius sialotranscriptomes presents clear evidence of such enzymes, but the activity in salivary homogenates was never studied.

Lacking in these Heteroptera sialotranscriptomes are additional nucleotide-acting enzymes, such as endonucleases, found in mosquitoes and sand flies [99-101], and adenosine deaminase, found also in mosquito and some, but not all, sand flies [102-104]. 
TABLE 3: Classification of the protein families relevant to secreted products in the Hemiptera/Heteroptera.

\begin{tabular}{|c|c|c|c|c|}
\hline Classification & No. of proteins & Genera found $^{1}$ & Function characterized $?^{2}$ & References \\
\hline \multicolumn{5}{|l|}{ Ubiquitous protein families } \\
\hline \multicolumn{5}{|l|}{ Enzymes } \\
\hline Cimex apyrase & 1 & $\mathrm{C}, \mathrm{R}(?)$ & $\mathrm{Y}$ & {$[26,50]$} \\
\hline $5^{\prime}$-nucleotidase & 6 & $\mathrm{~T}$ & $\mathrm{Y}$ & {$[12,13,51]$} \\
\hline Cimex NUDIX hydrolase & 3 & $\mathrm{C}$ & & \\
\hline Secreted esterase & 5 & $\mathrm{C}, \mathrm{T}$ & & \\
\hline $\begin{array}{l}\text { Inositol phosphate phosphatases including } \\
\text { Cimex nitrophorins }\end{array}$ & 24 & $\mathrm{C}, \mathrm{T}, \mathrm{R}$ & $\mathrm{Y} / \mathrm{N}$ & {$[8,27,28]$} \\
\hline Serine proteases & 17 & $\mathrm{C}, \mathrm{T}$ & $\mathrm{Y} / \mathrm{N}$ & {$[30]$} \\
\hline Chitinase & 1 & $\mathrm{O}$ & & \\
\hline Other enzymes & 4 & $\mathrm{~T}, \mathrm{O}$ & & \\
\hline \multicolumn{5}{|l|}{ Protease inhibitor domains } \\
\hline Kazal domain containing proteins & 13 & $\mathrm{~T}$ & & \\
\hline Serpin & 1 & $\mathrm{C}$ & & \\
\hline Pacifastin-related peptide & 1 & $\mathrm{O}$ & & \\
\hline Cystatin & 5 & $\mathrm{O}$ & & \\
\hline Lipocalins & 331 & $\mathrm{~T}, \mathrm{R}$ & $\mathrm{Y} / \mathrm{N}$ & $\begin{array}{l}{[2,4-7,11,14,15,19} \\
\quad 21,23,43,52-55]\end{array}$ \\
\hline Salivary OBP & 19 & $\mathrm{C}, \mathrm{T}, \mathrm{R}$ & & \\
\hline Salivary antigen 5 family & 22 & $\mathrm{C}, \mathrm{T}, \mathrm{R}$ & & \\
\hline Triatoma dimidiata lectin & 2 & $\mathrm{~T}$ & & \\
\hline \multicolumn{5}{|l|}{ Immunity related } \\
\hline Lysozyme & 4 & $\mathrm{C}$ & & \\
\hline Defensin & 1 & $\mathrm{~T}$ & & \\
\hline Histidine-rich peptide & 1 & $\mathrm{~T}$ & & \\
\hline Immune-related conserved insect protein & 1 & $\mathrm{~T}$ & & \\
\hline \multicolumn{5}{|l|}{ Arthropod or insect specific families } \\
\hline Cuticle-like proteins and conserved mucins & 5 & $\mathrm{~T}$ & & \\
\hline Conserved insect secreted protein family & 6 & $\mathrm{C}, \mathrm{T}, \mathrm{O}$ & & \\
\hline Mys2 family & 3 & $\mathrm{R}, \mathrm{T}$ & & \\
\hline Cimex-Triatoma family & 3 & $\mathrm{C}, \mathrm{T}$ & & \\
\hline $\begin{array}{l}\text { Other individual proteins of conserved insect } \\
\text { families }\end{array}$ & 4 & $\mathrm{~T}$ & & \\
\hline \multicolumn{5}{|l|}{ Hemiptera specific families } \\
\hline Mys3/hemolysin-like family & 16 & $\mathrm{~T}, \mathrm{R}, \mathrm{O}$ & & \\
\hline \multicolumn{5}{|l|}{ Triatoma-specific families } \\
\hline Trialysin & 8 & $\mathrm{~T}$ & $\mathrm{Y}$ & {$[17,18]$} \\
\hline Short trialysin & 6 & $\mathrm{~T}$ & & \\
\hline Triatoma matogrossensis family & 2 & $\mathrm{~T}$ & & \\
\hline Triatoma matogrossensis family 2 & 2 & $\mathrm{~T}$ & & \\
\hline Orphan Triatoma proteins & 19 & $\mathrm{~T}$ & & \\
\hline \multicolumn{5}{|l|}{ Rhodnius-specific families } \\
\hline $\begin{array}{l}\text { Orphan Rhodnius proteins, include } \\
\text { low-complexity proteins }\end{array}$ & 3 & $\mathrm{R}$ & & \\
\hline \multicolumn{5}{|l|}{ Cimex-specific proteins } \\
\hline Cimex mucin family & 2 & $\mathrm{C}$ & & \\
\hline Orphan Cimex proteins & 1 & $\mathrm{C}$ & & \\
\hline
\end{tabular}


TABle 3: Continued.

\begin{tabular}{lcccc}
\hline Classification & No. of proteins & Genera found & ${\text { Function characterized } ?^{2}}$ & References $^{\text {Oncopeltus-specific families }}$ \\
Oncopeltus family & 3 & & & \\
Oncopeltus family 2 & 2 & $\mathrm{O}$ & \\
Orphan Oncopeltus protein & 12 & $\mathrm{O}$ & \\
\hline Total & 559 & & & \\
\hline
\end{tabular}

${ }^{1}$ C: Cimex; T: Triatoma/Dipetalogaster/Panstrongylus; R: Rhodnius; O: Oncopeltus.

${ }^{2} \mathrm{Y}$ : yes; $\mathrm{Y} / \mathrm{N}$ : characterization of a few or a single member of the family.

3.1.2. Acetylcholinesterases. Four well-expressed and closely related isoforms of a typical acetylcholinesterase enzyme were found in the sialotranscriptome of C. lectularius [45]. A single transcript from the same family was also found in Triatoma matogrossensis. Although most acetylcholinesterases are extracellular membrane-bound enzymes by virtue of a glycophosphatidyl-inositol membrane anchor in their carboxy termini, these Cimicomorpha enzymes lack this terminal region, and thus these enzymes are secreted. The role of these enzymes in blood feeding is not yet apparent.

3.1.3. Inositol Triphosphate Phosphatases (IPPase) Including Cimex Nitrophorin. This family of proteins has been found ubiquitously in the sialomes of bloodsucking Cimicomorpha, including the well-characterized enzyme from R. prolixus [8] and the C. lectularius nitrophorin [27-29], a protein found associated with a heme moiety and a carrier and stabilizer of nitric oxide (NO), a very reactive gaseous substance that is also a potent vasodilator and platelet aggregation inhibitor. While the function of Cimex nitrophorin is without question, the function of an extracellular inositol phosphatase is puzzling, because these inositol phosphates are intracellular and not available to an extracellular enzyme. Indeed, it appears fitting that inositol polyphosphates should be hydrolyzed, because they perform a proplatelet aggregation function as well as proinflammatory and immuneenhancing roles in leukocytes $[105,106]$. Perhaps the enzyme may reach the intracellular pool by some not yet understood mechanism. On the other hand, association of heme with inositol phosphatases seen in the case of Cimex nitrophorins is not at all common, being unique to these proteins; investigation of the amino acids that are associated with heme binding does not reveal similarities to other IPPases from either vertebrates or invertebrates (Ribeiro, unpublished).

The phylogram of the IPPase sequences found in Additional File 1 (Figure 1) shows the Cimex nitrophorins contained within a strong clade with $100 \%$ bootstrap support and constituted by at least three subclades representing at least three genes expressing these NO transporters, plus alleles or other genes. Cimex has two additional sequences outside the nitrophorin clade and near the IPPase clade of the remaining triatomines. It is thus interesting that both Cimex and triatomines have a common IPPase in their sialome, even though we have no idea of their function. IPPases have not been found in any other transcriptome so far done, including those of mosquitoes, sand flies, biting midges, black flies, and ticks, being thus uniquely from Cimicomorpha blood feeders.

3.1.4. Serine Proteases. Serine proteases are commonly found in the sialotranscriptomes of insects and ticks, as well as in those of Heteroptera. An unusual serine protease activity in the saliva of $T$. infestans has been noted before, but only a partial enzyme purification of the enzyme, named triapsin, was achieved [107]. Within the bloodsucking Heteroptera, only one Panstrongylus megistus sequence has been molecularly characterized as a fibrinolytic enzyme [30]. Additional File 1 shows such proteins from Cimicomorpha, including plantfeeding bugs such as Lygus lineolaris, Lygus hesperus, and Creontiades dilutus [108-110]. The phylogram of these enzymes (Figure 2) shows two well-defined clades, one containing most of the Lygus sequences, but also two T. matogrossensis and one T. brasiliensis sequence, within a clade of $86 \%$ bootstrap support, suggesting a common ancestral salivary serine protease for plant- and blood-feeding Cimicomorpha. The fibrinolytic enzyme of Panstrongylus shares a strongly supported clade with two other T. matogrossensis sequences, which are probable orthologs of the Panstrongylus gene. The Cimex sequence appears as an outlier to the group. Rhodnius sialotranscriptomes have not revealed proteases, and its saliva does not hydrolyze the substrates used in the characterization of the T. infestans triapsin (Ribeiro, unpublished).

3.1.5. Other Enzymes. A chitinase and a lipase were found in Oncopeltus, while T. matogrossensis displayed a salivary phospholipase and a metalloprotease. The precise role of these enzymes is unknown. Salivary metalloproteases in ticks have been associated with fibrinolytic and antiangiogenic activities $[111,112]$, while the Oncopeltus enzyme may be associated with digestive or antifungal functions.

\subsection{Protease Inhibitor Domains}

3.2.1. Kazal Domain-Containing Peptides. The Kazal domain occurs in many protease inhibitors, and its structure was first determined for the proteinase inhibitor IIA from bull seminal plasma [113]. The sialotranscriptome of members of South American Triatoma (T. infestans, T. matogrossensis, and T. brasiliensis) but not North American T. dimidiata or T. rubida, nor any other sialotranscriptome of Cimicomorpha, abounds with transcripts coding for proteins containing this 


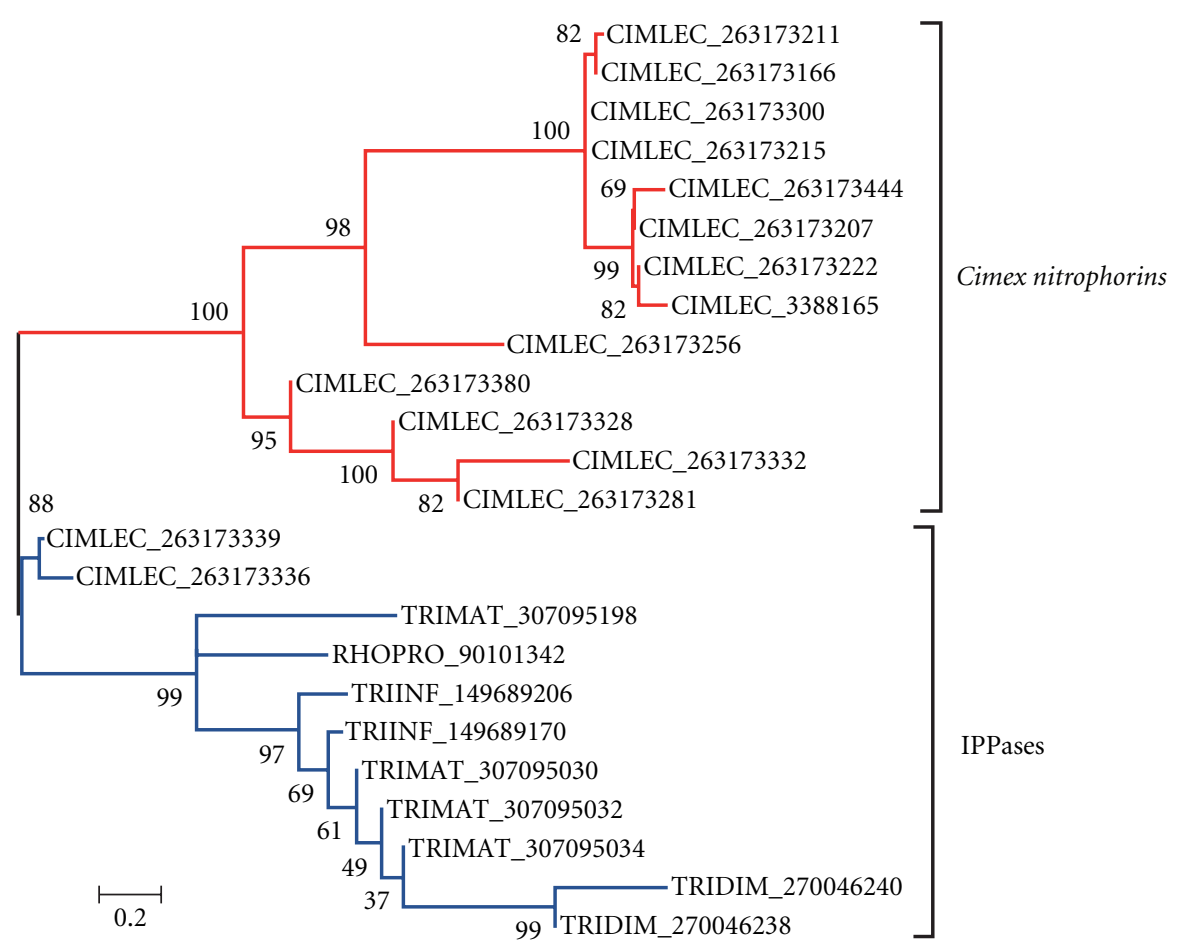

FIGURE 1: Phylogram of the inositol triphosphate phosphatase family of Cimicomorpha. The sequences are named with the first 3 letters of the genus name, followed by the first 3 letters of the species name, followed by their GenBank GI accession number. The sequences were aligned by Clustal, and the neighbor-joining bootstrapped phylogram was obtained with the MEGA package with 10,000 iterations, Poisson model of amino acid substitution and pairwise amino acid comparisons using the gamma rate of amino acid substitution (gamma parameter $=1$ ). The numbers at the nodes are the percent bootstrap support. The line at the base indicates the rate of amino acid substitution per site.



FIgURE 2: Phylogram of the salivary serine proteases of Cimicomorpha. See the legend of Figure 1 for more details.

domain; however, none have been so far characterized functionally. In Rhodnius, Triatoma, and Dipetalogaster, the crop antithrombin has been characterized as a protein containing two such domains [114-117], but salivary anticlotting of Rhodnius and Triatoma has been shown to be different lipocalins named prolixin $S$ and triabin $[2,21,118]$. Kazaltype peptides can function as antimicrobials by inhibiting microbial exoproteases essential for their survival $[119,120]$ and can also work as vasodilators, as in the case of a tabanid salivary protein named vasotab, which is suspected to modify 
ion channels [121]. These functions should be taken into consideration in functional assays of the recombinant Kazal peptides.

3.2.2. Serpin. The serine protease inhibitor (serpin) family is ubiquitous in nature, functioning mostly as endogenous regulators of proteolytic cascades such as inhibiting thrombin in vertebrates (plasmatic antithrombin 3 ) or regulating phenol oxidase activation cascades in invertebrates $[122,123]$. The salivary anticlotting proteins of Aedes mosquitoes (but not those of anopheline mosquitoes) are members of this family $[124,125]$. A single sequence of this family, derived from four ESTs, was found in the sialotranscriptome of C. lectularius. Its target is still unknown.

3.2.3. Pacifastin and Cystatin. Proteins containing these domains were only found in the sialotranscriptome of Oncopeltus. Pacifastins are typical serine protease inhibitors of insects and crustaceans [126], while cystatins are ubiquitous proteins typically inhibiting cysteine proteases [127]. Although a single EST was found coding for the pacifastin peptide, five well-expressed cystatins were identified in Oncopeltus. The targets of these peptides are unknown, but it was suggested that the salivary cystatins may prevent plant apoptosis induced by cysteine proteases [46, 128, 129]. Tick sialomes have revealed cystatins that were shown to inhibit inflammation and maturation of dendritic cells in their hosts [130].

3.3. Lipocalins. The term lipocalin literally means a cup of lipid, as these proteins form a barrel with a hydrophobic interior cavity that is suitable to transport lipids and other hydrophobic compounds in an aqueous milieu [131-133]. There is virtually no sequence conservation in the family, which is recognized by its typical 3D structure composed of a repeated +1 topology $\beta$-barrel. This protein family is by far the most abundant in sialotranscriptomes of triatomine bugs (see review [132]) but remarkably absent in Cimex and Oncopeltus; however, it was also abundantly recruited in tick sialomes [56], another case of convergent evolution. Additional File 1 provides for 331 lipocalins, which is more than half of all putative secreted proteins listed in this work. Several of these proteins may be alleles of the same gene. The sheer size of the family in individual species is indicative of gene duplication events that might have had an impact during the evolution of blood-feeding [134136]. Following gene duplication-by retrotransposition or more commonly by forming tandem repeats due to transposable element recombination-the new genes can lead to an increased transcript load in a particular organ or tissue. If this augmented expression increases fitness (e.g., helps the bug to feed), the gene will persist; otherwise, it will evolve to be a pseudogene [137]. Once genes are duplicated and fitness is increased by the duplication, these are free to evolve independently and to diverge from each other by acquisition of novel functions. Salivary genes of bloodsucking arthropods are under selection by two different processes. First, the gene can evolve in the direction of fine tuning its function in relationship to its target. For example, a bug feeding on a bird may have "ideal" anticlotting, but if ecologic changes appear and the bug shifts to another host, this anticlotting may still work but have some room for improvement (e.g., by increasing its affinity to the specific thrombin). Second, any protein injected into the skin of a vertebrate is capable of eliciting an immune reaction, which may lead to defensive host behavior following mast cell degranulation or complement-mediated local inflammation, leading to interruption of the meal or killing of the insect. This may lead to a scenario of balanced polymorphism, with the least common epitope being the best one to have, thus multiplying the number of different alleles in a population that are selected to have the same optimal function but the least common antigenicity. Host immune pressure can also lead to gene obsolescence, creating a niche for cooption (exaptation) of new genes, including horizontal transfer [138], which may substitute for the lost function and thus may explain the appearance of novel salivary genes in related organisms [139].

Lipocalin functions in triatomines are multiple and linked to their unique barrel when working as kratagonists (from the Greek kratos = seize) [140], which are binders of relatively small agonists such as biogenic amines, $\mathrm{TXA}_{2}$, leukotrienes, or ADP, or carrying the heme that carries NO in Rhodnius nitrophorins, or functions linked to their side chains when they work as anticlotting agents such as triabin (for references for these functions, see Table 1). Uniquely, the protein nitrophorin 2 from $R$. prolixus has three functions: (i) it carries NO, (ii) it binds histamine, and (iii) it is an inhibitor of the activation of Factor X [5, 141]. Notice that contrary to their names as "lipid cups," many of these lipocalin ligands are well charged and not hydrophobic, such as biogenic amines and ADP. The functions of the salivary lipocalins in ticks are similarly associated with their kratagonist activity toward biogenic amines or arachidonic acid derivatives, or as inhibitors of complement activation [142-148].

A phylogram of the triatomine lipocalins, although a bit overwhelming in size, presents a bird's-eye view of the several distinct families arranged mostly in robust clades (Figure 3 and Additional File 2). Most clades have not a single member that has been analyzed functionally (marked with Roman numerals in Figure 3), including the clade containing the Triatoma protracta antigen procalin; accordingly there are eight clades that have no known function. Additional File 2 is provided for high-resolution display of the sequences, which have their NCBI accession numbers for sequence retrieval. A few details deserve some comments with respect to the phylogram. (i) The clade named Pal-Tri-Dip contains the Triatoma proteins pallidipin, triplatin, and the Dipetalogaster protein dipetalodipin, which are platelet inhibitors possibly all due to being $\mathrm{TXA}_{2}$ kratagonists as demonstrated for triplatin and dipetalodipin [25], thus indicating the conservation of this function among two different genera. (ii) Most Rhodnius lipocalins cluster in two clades, one containing all the known NO carriers, named nitrophorins (NP) and the other containing the adenosine nucleotide kratagonists named RPAI (Rhodnius platelet aggregation inhibitor). (iii) The Rhodnius biogenic amine-binding protein (BABP) 


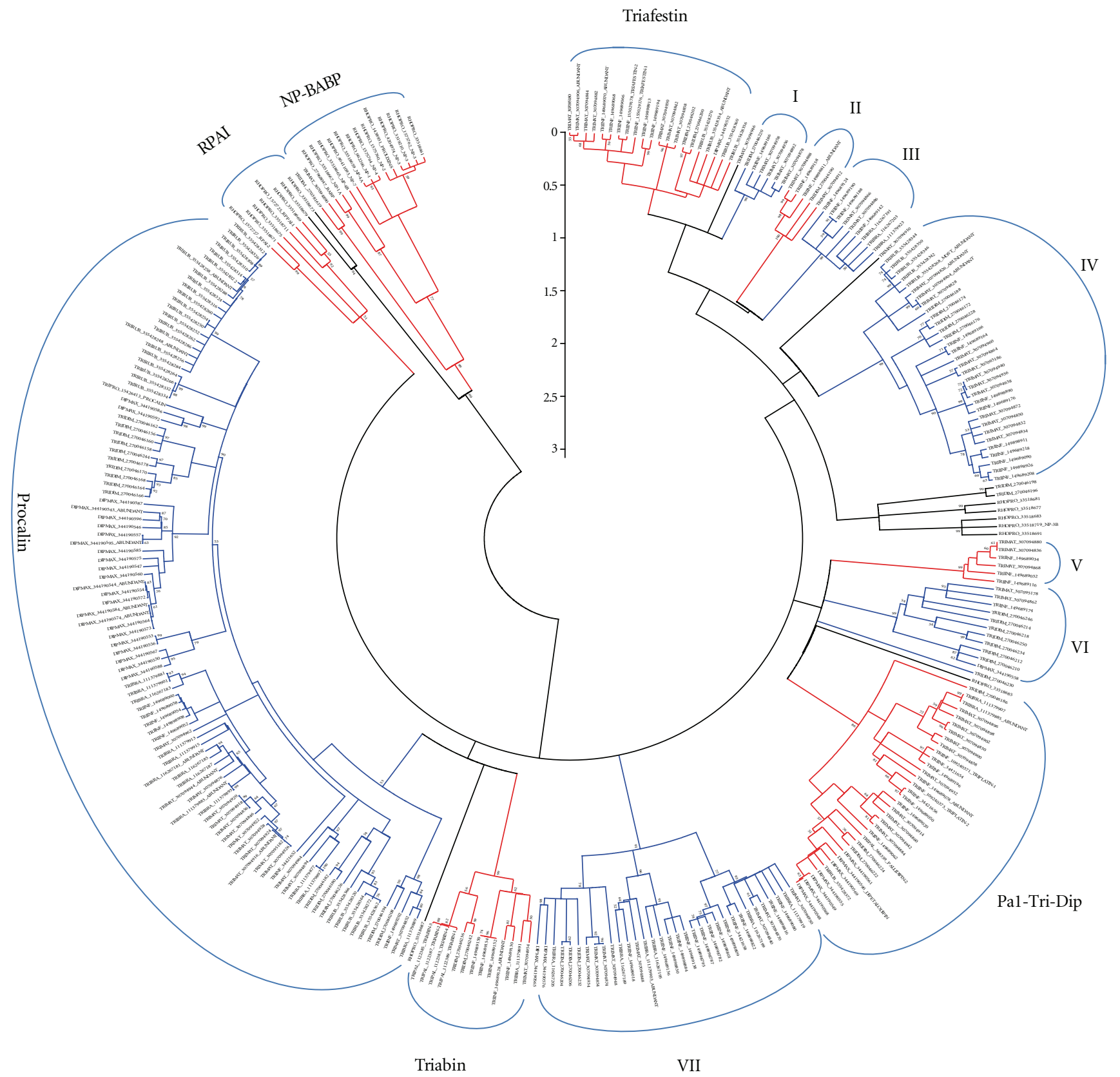

Figure 3: Phylogram of the salivary lipocalin family of triatomines. Clades containing members that have been functionally characterized are named according to these proteins. Other clades are named with Roman numerals. Except for the triafestin clade, other clades have $>70 \%$ bootstrap support. The sequences are named with the first 3 letters of the genus name, followed by the first 3 letters of the species name, followed by their GenBank gi| accession number. When the protein has been functionally characterized, its name is also included after the NCBI number. Abundantly expressed proteins are also marked to indicate this fact. The numbers in the bar indicate the rate of amino acid substitution per site. For other details, see Figure 1 legend.

somewhat surprisingly clusters with the nitrophorins, but BABP does not have a heme group and has higher affinity for serotonin and norepinephrine, constituting a good example of gene duplication and divergence of function [7]. (iv) Exceptionally, one T. matogrossensis and one T. dimidiata protein sequence group with the NP-BABP clade with $99 \%$ bootstrap support. The function of these proteins could lead to the original function of the Rhodnius nitrophorins, which are exclusive of the genus Rhodnius. Indeed the abundance of these heme proteins in Rhodnius salivary glands makes these glands distinctively bright cherry red in color, as first pointed out by Wigglesworth nearly 70 years ago [149]. Triatoma and Dipetalogaster glands are clear or of a very pale yellow color [150]. (v) Rhodnius lipocalins not belonging to the NP-BABP and RPAI clades are scattered in the phylogram, including one sequence between the procalin and triabin 
clades, one between the triabin and VI clades, and a group of four proteins between clades IV and V. None of these Rhodnius proteins group within strong bootstrap support to any of the Dipetalogaster- or Triatoma-containing clades. (vi) Finally, the procalin clade is very extensive and contains many robust subclades, many of which are of single species, indicating possible recent events of gene duplication or extensive polymorphism.

3.4. Odorant/Pheromone-Binding Family (OBP). The OBP family, like the lipocalins, is specialized in carrying small hydrophobic ligands in aqueous media [151, 152]. A modified version of the odorant-binding family of proteins is very abundant in the sialotranscriptomes of hematophagous Nematocera [138] and named as the D7 protein family. A few mosquito proteins have been crystallized and functionally characterized, showing kratagonist activity toward biogenic amines, $\mathrm{TXA}_{2}$, and leukotrienes, in addition to anticlotting activity [153-156].

In hematophagous Cimicomorpha, members of the OBP family are found in Rhodnius, Triatoma, and Cimex but are particularly abundant in Cimex, with two OBP proteins having over 250 ESTs in a total of $\sim 2,000$ ESTs, suggesting the OBP family has been recruited by Cimex to function as the lipocalins in triatomines. No salivary member of this family in Cimicomorpha has been so far functionally characterized.

3.5. Antigen-5 Family. This is a ubiquitous protein family found in plants and animals, including expression in the venom glands of vespids, where it was recognized as an antigen, thus the name antigen 5 for this family. They are members of the CAP superfamily, most with unknown function [157]. In snakes and lizards, they have been associated with venom toxins [158-160]. In stable flies, one salivary antigen 5 protein binds immunoglobulins and may function as an inhibitor of the classical pathway of complement activation [161]. In horse flies, one protein has acquired a disintegrin motif and is a strong inhibitor of platelet aggregation [162-164]. All triatomine sialotranscriptomes have revealed this class of proteins, which is particularly abundant in Dipetalogaster. The function of these proteins in triatomine blood feeding is still unknown.

3.6. Lectin. Triatoma dimidiata exclusively presents two partial sequences containing a galactose-binding domain. While lectins-mainly C-type lectins-have been described in the sialotranscriptome of mosquitoes (none with known function), this is so far a unique finding in triatomine sialotranscriptomes.

3.7. Immunity-Related, Ubiquitous Families. Immunityrelated proteins and peptides are commonly found in the saliva of bloodsucking arthropods and may help to control microbial growth in the ingested meal and perhaps also avoid microbial infection of the bite site. Lysozyme, while common in mosquito sialomes, is found exclusively so far in Cimex sialomes, with four quite different proteins being reported. $D$. maxima presents a histidine-rich peptide that could function as an antimicrobial peptide, and a defensin is reported from $T$. infestans. The absence of commonly found salivary antimicrobial peptides in triatomines suggests that if this salivary function is present within these organisms, it may be encoded by lineage-specific gene families, one of which (trialysin) will be reported further below.

\section{Arthropod-Specific Families}

Several insect-specific families are further identified, none functionally characterized, and most without domains providing a clue for their function. These include proteins with chitin-binding domains and cuticle-like homologs, which may be associated with salivary ducts rather than a function in the injected saliva. One conserved secreted insect protein family of basic peptides having $\sim 100$ amino acids after signal peptide cleavage occurs in Cimex, Oncopeltus, and Triatoma sialotranscriptomes. Homologs are found by blastp to the nonredundant (NR) protein database including a venom protein from the wasp parasitoid Nasonia vitripennis identified in a proteomic study [165]. Exceptionally, there are also homologs to proteins from the soil bacteria Streptomyces clavuligerus, having $52 \%$ identity to the insect proteins. Similarly, the protein originally described in $R$. prolixus as MYS2 has homologs found in the sialotranscriptomes of $T$. brasiliensis and T. matogrossensis and is similar to many other insect proteins in the NR, including protein sequences deducted from the sialotranscriptome of the tsetse Glossina morsitans [166]. Three sequences, one each from C. lectularius, T. infestans, and T. matogrossensis, have $25 \%$ amino acid sequence identity but $52 \%$ similarity and little similarity to other proteins on the NR database. These sequences are grouped in Additional File 1 as the CimexTriatoma family. PSI-blast initiated by the T. matogrossensis sequence against the NR database initially retrieves only the two other sequences, but on first iteration it retrieves dozens of insect proteins (Additional File 3), and in the third iteration it retrieves Daphnia and tick proteins, suggesting this is an arthropod family of high divergence. Finally, the sialotranscriptome of $T$. matogrossensis identified four additional nonrelated proteins that have insect homologs but were not found in other reported sialotranscriptomes of Hemiptera but are similar to proteins reported from G. morsitans and from Aedes aegypti sialotranscriptomes. It is possible that these families function as antimicrobial peptides, but so far none has been characterized.

\section{Hemiptera-Specific Families}

5.1. Mys3/Hemolysin Family. When the R. prolixus sialotranscriptome was reported [36], an additional mysterious protein was named Mys3. Later, with additional sialotranscriptome reports, another protein family emerged, named as hemolysin-like because some members had weak similarity to bacterial proteins annotated as hemolysins. PSI-blast later revealed that these proteins all belong to a single family that is quite divergent, including a truncated protein from the sialome of Oncopeltus, suggesting a non-blood-feeding role, perhaps antimicrobial, for its members. 
5.2. Triatoma-Specific Families. Sialotranscriptomes of several species of the Triatoma genus reveal several unique protein families, among which are the trialysin and short trialysin families. The trialysins are basic proteins of mature MW near $26 \mathrm{kDa}$ that can be further processed to peptides that have lytic properties $[17,18]$ and may function as antimicrobials. Short trialysins have mature MW of $\sim 6.1$ and acidic pI and are so named because they match the amino terminal region of the mature trialysins. Both forms are abundantly expressed but only found in T. infestans and T. matogrossensis, which are from southern South America, and are not found in the sialotranscriptomes of T. brasiliensis, found in northeastern Brazil, or on those of the North American T. dimidiata or T. rubida. Additional File 1 reports 19 protein sequences from Triatoma that are not similar to anything deposited in the NR database and two pairs of sequences from T. matogrossensis that only match its pair members. None has been functionally characterized. It is interesting that of these 23 sequences only one derives from T. rubida and the remaining derive from T. infestans and $T$. matogrossensis, although the number of clones sequenced for the $T$. brasiliensis, $T$. dimidiata, and T. rubida was similar to those of $T$. infestans and T. matogrossensis, suggesting a greater sialome diversity in these bugs from southern South America.

5.3. Rhodnius-, Cimex-, and Oncopeltus-Specific Families. Additional File 1 presents 16 proteins from the bugs named above that have no significant matches to the NR database except in some cases for some proteins of low complexity. None of these proteins has been functionally characterized. This includes Rhodnius MY1 protein, one of three mysterious proteins revealed in the first bug sialotranscriptome [36]. As seen above, MYS2 and MYS3 were later found to be members of larger families. It is expected that, with a larger number of genomes and transcriptomes sequenced, MYS1-as well as the other orphan proteins in this group-will also be deorphanized.

\section{Housekeeping Proteins}

Mostly from the sialotranscriptomes shown in Table 2, many housekeeping protein sequences were also deduced, including many associated with energy metabolism, protein synthesis, modification, and export, among other classes (see worksheet named "Housekeeping" of Additional File 1). Interestingly, the sialotranscriptome of Triatoma rubida shows abundant expression of members of the cytochrome P450 as well as of the 15-hydroxyprostaglandin dehydrogenase, suggesting either that the salivary gland may have an active endogenous prostaglandin signaling or that prostaglandins may be secreted in the saliva of these bugs. Cyt P450 transcripts were also detected in Rhodnius and T. matogrossensis, and the prostaglandin dehydrogenase was also found in T. infestans. Increased depth of sequencing of these sialotranscriptomes may certainly reveal these two classes of proteins to be expressed in all triatomines.

\section{Concluding Remarks}

Blood-feeding Cimicomorpha have developed a sophisticated and divergent array of salivary pharmacologically active compounds that disarm their hosts' reaction against blood loss. In a few transcriptomes encompassing members of the Reduviidae and Cimicidae, the convergent evolution scenario in the sialomes of these two families is apparent. Both have apyrase activity, but from different gene families; Cimex and Rhodnius (but not any Triatomini member) use $\mathrm{NO}$ as a vasodilator but co-opted completely different heme proteins to carry this unstable gas. The anticlotting compounds are different at the Reduviidae tribe level and so on. The lipocalin expansion is remarkable among the triatomines and nonexistent in Cimex. These proteins can play many different functions as binders of small agonists (kratagonists), NO carriers, or protease inhibitors. In Cimex, the expanded odorant binding family may have taken this role, but none thus far has been characterized.

Notice that the sialome of Oncopeltus, a member of the Pentatomomorpha - the most closely related suborder to the Cimicomorpha (see http://tolweb.org/Heteroptera/10805) $[76,167]$ - revealed virtually nothing in common with the Cimicomorpha, and the Cimicidae sialome also revealed little in common with the Reduviidae, perhaps as expected by the divergence of these families (see http://tolweb.org/Cimicomorpha/10817). Zooming-in on the Triatomine group, it will be interesting in the future to describe the sialomes of additional tribes of the Triatomine, such as the Bolboderini, which includes bugs that feed on insect hemolymph, the Cavernicolini that are associated with bats, and members of the Linshcosteus genus that are found in India [168] and could be divergent members. Zooming a little out and as indicated by Schofield and Galvão [49], facultative blood feeding is found in non-Triatominae members of the Reduviidae, including the Emesinae, Harpactorinae, Peiratinae, Physoderinae, and Reduviinae. Sialomes of these subfamilies could be more indicative of the prevalent "preadaptations" available as stepping stones and promoted by the blood-feeding habit. On the other hand, the Cimicidae are closely related to the bat bugs (Polyctenidae), which is a sister group, and to the Anthocoridae (flower bugs; http://tolweb.org/Cimicomorpha/10817), which feed on small insects. These non-blood-feeding closer relatives may reveal insights into the Cimicidae evolution to hematophagy.

\section{Acknowledgments}

This work was supported by the Intramural Research Program of the Division of Intramural Research, the National Institute of Allergy and Infectious Diseases, and the National Institutes of Health. The authors thank NIAID DIR intramural editor Brenda Rae Marshall for editing the manuscript. Because JMCR and IMBF are government employees and this is a government work, the work is in the public domain in the United States. Notwithstanding any other agreements, the NIH reserves the right to provide the work to PubMedCentral for display and use by the public, and 
PubMedCentral may tag or modify the work consistent with its customary practices. You can establish rights outside of the US subject to a government use license.

\section{References}

[1] D. Grimaldi and M. Engel, Evolution of the Insects, Cambridge University Press, New York, NY, USA, 2005.

[2] J. M. C. Ribeiro, M. Schneider, and J. A. Guimaraes, "Purification and characterization of prolixin $S$ (nitrophorin 2), the salivary anticoagulant of the blood-sucking bug Rhodnius prolixus," Biochemical Journal, vol. 308, no. 1, pp. 243-249, 1995.

[3] I. M. B. Francischetti, J. F. Andersen, and J. M. C. Ribeiro, "Biochemical and functional characterization of recombinant Rhodnius prolixus platelet aggregation inhibitor 1 as a novel lipocalin with high affinity for adenosine diphosphate and other adenine nucleotides," Biochemistry, vol. 41, no. 11, pp. 3810-3818, 2002.

[4] I. M. B. Francischetti, J. M. C. Ribeiro, D. Champagne, and J. Andersen, "Purification, cloning, expression, and mechanism of action of a novel platelet aggregation inhibitor from the salivary gland of the blood-sucking bug, Rhodnius prolixus," The Journal of Biological Chemistry, vol. 275, no. 17, pp. 12639-12650, 2000.

[5] J. F. Andersen and W. R. Montfort, "The crystal structure of nitrophorin 2. A trifunctional antihemostatic protein from the saliva of Rhodnius prolixus," The Journal of Biological Chemistry, vol. 275, no. 39, pp. 30496-30503, 2000.

[6] J. M. C. Ribeiro and F. A. Walker, "High affinity histaminebinding and antihistaminic activity of the salivary nitric oxide-carrying heme protein (nitrophorin) of Rhodnius prolixus," Journal of Experimental Medicine, vol. 180, no. 6, pp. 2251-2257, 1994.

[7] J. F. Andersen, I. M. B. Francischetti, J. G. Valenzuela, P. Schuck, and J. M. C. Ribeiro, "Inhibition of hemostasis by a high affinity biogenic amine-binding protein from the saliva of a blood-feeding insect," The Journal of Biological Chemistry, vol. 278, no. 7, pp. 4611-4617, 2003.

[8] J. F. Andersen and J. M. C. Ribeiro, "A secreted salivary inositol polyphosphate 5-phosphatase from a blood-feeding insect: allosteric activation by soluble phosphoinositides and phosphatidylserine," Biochemistry, vol. 45, no. 17, pp. 54505457, 2006.

[9] D. M. Golodne, R. Q. Monteiro, A. V. Graça-Souza, M. A. C. Silva-Neto, and G. C. Atella, "Lysophosphatidylcholine acts as an anti-hemostatic molecule in the saliva of the bloodsucking bug Rhodnius prolixus," The Journal of Biological Chemistry, vol. 278, no. 30, pp. 27766-27771, 2003.

[10] J. M. C Ribeiro, J. M. H Hazzard, R. H. Nussenzveig, D. E. Champagne, F. A. Walker et al., "Reversible binding of nitric oxide by a salivary nitrosylhemeprotein from the blood sucking bug, Rhodnius prolixus," Science, vol. 260, Article ID 5107, pp. 539-541, 1993.

[11] D. E. Champagne, R. H. Nussenzveig, and J. M. C. Ribeiro, "Purification, partial characterization, and cloning of nitric oxide- carrying heme proteins (nitrophorins) from salivary glands of the blood-sucking insect Rhodnius prolixus," The Journal of Biological Chemistry, vol. 270, no. 15, pp. 86918695, 1995.

[12] E. Faudry, S. P. Lozzi, J. M. Santana et al., "Triatoma infestans apyrases belong to the 5'-nucleotidase family," The Journal of Biological Chemistry, vol. 279, no. 19, pp. 19607-19613, 2004.
[13] E. Faudry, J. M. Santana, C. Ebel, T. Vernet, and A. R. L. Teixeira, "Salivary apyrases of Triatoma infestans are assembled into homo-oligomers," Biochemical Journal, vol. 396, no. 3, pp. 509-515, 2006.

[14] A. Morita, H. Isawa, Y. Orito, S. Iwanaga, Y. Chinzei, and M. Yuda, "Identification and characterization of a collageninduced platelet aggregation inhibitor, triplatin, from salivary glands of the assassin bug, Triatoma infestans," FEBS Journal, vol. 273, no. 13, pp. 2955-2962, 2006.

[15] D. Ma, T. C. F. Assumpcao, Y. Li, J. F. Andersen, J. Ribeiro, I. M. B. Francischetti et al., "Triplatin, a platelet aggregation inhibitor from the salivary gland of the triatomine vector of chagas disease, binds to TXA2 but does notinteract with GPVI," Thrombosis and Haemostasis, vol. 1, no. 107, pp. 111123, 2011.

[16] H. Isawa, Y. Orito, N. Jingushi et al., "Identification and characterization of plasma kallikrein-kinin system inhibitors from salivary glands of the blood-sucking insect Triatoma infestans," FEBS Journal, vol. 274, no. 16, pp. 4271-4286, 2007.

[17] R. M. Martins, M. L. Sforça, R. Amino et al., "Lytic activity and structural differences of amphipathic peptides derived from trialysin," Biochemistry, vol. 45, no. 6, pp. 1765-1774, 2006.

[18] R. Amino, R. M. Martins, J. Procopio, I. Y. Hirata, M. A. Juliano, and S. Schenkman, "Trialysin, a novel pore-forming protein from saliva of hematophagous insects activated by limited proteolysis," The Journal of Biological Chemistry, vol. 277, no. 8, pp. 6207-6213, 2002.

[19] C. Noeske-Jungblut, J. Krätzschmar, B. Haendler et al., "An inhibitor of collagen-induced platelet aggregation from the saliva of Triatoma pallidipennis," The Journal of Biological Chemistry, vol. 269, no. 7, pp. 5050-5053, 1994.

[20] B. Haendler, A. Becker, C. Noeske-Jungblut, J. Kratzschmar, P. Donner, and W. D. Schleuning, "Expression of active recombinant pallidipin, a novel platelet aggregation inhibitor, in the periplasm of Escherichia coli," Biochemical Journal, vol. 307, no. 2, pp. 465-470, 1995.

[21] C. Noeske-Jungblut, B. Haendler, P. Donner, A. Alagon, L. Possani, and W. D. Schleuning, "Triabin, a highly potent exosite inhibitor of thrombin," The Journal of Biological Chemistry, vol. 270, no. 48, pp. 28629-28634, 1995.

[22] E. Glusa, E. Bretschneider, J. Daum, and C. Noeske-Jungblut, "Inhibition of thrombin-mediated cellular effects by triabin, a highly potent anion-binding exosite thrombin inhibitor," Thrombosis and Haemostasis, vol. 77, no. 6, pp. 1196-1200, 1997.

[23] P. Fuentes-Prior, C. Noeske-Jungblut, P. Donner, W. D. Schleuning, R. Huber, and W. Bode, "Structure of the thrombin complex with triabin, a lipocalin-like exosite-binding inhibitor derived from a triatomine bug," Proceedings of the National Academy of Sciences of the United States of America, vol. 94, no. 22, pp. 11845-11850, 1997.

[24] C. D. Paddock, J. H. McKerrow, E. Hansell, K. W. Foreman, I. Hsieh, and N. Marshall, "Identification, cloning, and recombinant expression of procalin, a major triatomine allergen," Journal of Immunology, vol. 167, no. 5, pp. 2694-2699, 2001.

[25] T. C. F. Assumpção, P. H. Alvarenga, J. M. C. Ribeiro, J. F. Andersen, and I. M. B. Francischetti, "Dipetalodipin, a novel multifunctional salivary lipocalin that inhibits platelet aggregation, vasoconstriction, and angiogenesis through unique binding specificity: TXA2, PGF2 $\alpha$, and 15(S)-HETE," The Journal of Biological Chemistry, vol. 285, no. 50, pp. 39001-39012, 2010. 
[26] J. G. Valenzuela, R. Charlab, M. Y. Galperin, and J. M. C. Ribeiro, "Purification, cloning, and expression of an apyrase from the bed bug Cimex lectularius: a new type of nucleotidebinding enzyme," The Journal of Biological Chemistry, vol. 273, no. 46, pp. 30583-30590, 1998.

[27] J. G. Valenzuela, F. A. Walker, and J. M. Ribeiro, "A salivary nitrophorin (nitric-oxide-carrying hemoprotein) in the bedbug Cimex lectularius," Journal of Experimental Biology, vol. 198, pp. 1519-1526, 1995.

[28] J. G. Valenzuela and J. M. C. Ribeiro, "Purification and cloning of the salivary nitrophorin from the hemipteran Cimex lectularius," Journal of Experimental Biology, vol. 201, no. 18 , pp. 2659-2664, 1998.

[29] A. Weichsel, E. M. Maes, J. F. Andersen et al., "Heme-assisted S-nitrosation of a proximal thiolate in a nitric oxide transport protein," Proceedings of the National Academy of Sciences of the United States of America, vol. 102, no. 3, pp. 594-599, 2005.

[30] C. K. Meiser, H. Piechura, H. E. Meyer, B. Warscheid, G. A. Schaub, and C. Balczun, "A salivary serine protease of the haematophagous reduviid Panstrongylus megistus: sequence characterization, expression pattern and characterization of proteolytic activity," Insect Molecular Biology, vol. 19, no. 3, pp. 409-421, 2010.

[31] W. G. Friend and J. J. B. Smith, "Feeding in Rhodnius prolixus: mouthpart activity and salivation, and their correlation with changes of electrical resistance," Journal of Insect Physiology, vol. 17, no. 2, pp. 233-243, 1971.

[32] A. C. Soares, J. Carvalho-Tavares, N. D. F. Gontijo, V. C. dos Santos, M. M. Teixeira, and M. H. Pereira, "Salivation pattern of Rhodnius prolixus (Reduviidae; Triatominae) in mouse skin," Journal of Insect Physiology, vol. 52, no. 5, pp. 468-472, 2006.

[33] M. M. Lavoipierre, G. Dickerson, and R. M. Gordon, "Studies on the methods of feeding of blood-sucking arthropods. I. The manner in which triatomine bugs obtain their bloodmeal, as observed in the tissues of the living rodent, with some remarks on the effects of the bite on human volunteers," Annals of Tropical Medicine and Parasitology, vol. 53, pp. 235250, 1959.

[34] S. Dinant, J. L. Bonnemain, C. Girousse, and J. Kehr, "Phloem sap intricacy and interplay with aphid feeding," Comptes Rendus, vol. 333, no. 6-7, pp. 504-515, 2010.

[35] J. M. C. Ribeiro et al., "Insect saliva: function, biochemistry and physiology," in Regulatory Mechanisms of Insect Feeding, R. F. Chapman and G. de Boer, Eds., pp. 74-97, Chapman \& Hall, London, 1995.

[36] J. M. C. Ribeiro, J. Andersen, M. A. C. Silva-Neto, V. M. Pham, M. K. Garfield, and J. G. Valenzuela, "Exploring the sialome of the blood-sucking bug Rhodnius prolixus," Insect Biochemistry and Molecular Biology, vol. 34, no. 1, pp. 61-79, 2004.

[37] A. C. M. Bussacos, E. S. Nakayasu, M. M. Hecht et al., "Diversity of anti-haemostatic proteins in the salivary glands of Rhodnius species transmitters of Chagas disease in the greater Amazon," Journal of Proteomics, vol. 74, no. 9, pp. 1664-1672, 2011.

[38] T. C. F. Assumpção, I. M. B. Francischetti, J. F. Andersen, A. Schwarz, J. M. Santana, and J. M. C. Ribeiro, "An insight into the sialome of the blood-sucking bug Triatoma infestans, a vector of Chagas' disease," Insect Biochemistry and Molecular Biology, vol. 38, no. 2, pp. 213-232, 2008.

[39] A. Santos, J. M. C. Ribeiro, M. J. Lehane et al., "The sialotranscriptome of the blood-sucking bug Triatoma brasiliensis
(Hemiptera, Triatominae)," Insect Biochemistry and Molecular Biology, vol. 37, no. 7, pp. 702-712, 2007.

[40] T. C. Assumpção, D. P. Eaton, V. M. Pham et al., "An insight into the sialotranscriptome of Triatoma matogrossensis, a kissing bug associated with fogo selvagem in South America," American Journal of Tropical Medicine and Hygiene, vol. 86, no. 6, pp. 1005-1014, 2012.

[41] J. M. Ribeiro, T. C. Assumpção, V. M. Pham, I. M. Francischetti, C. E. Reisenman et al., "An insight into the sialotranscriptome of Triatoma rubida (Hemiptera: Heteroptera)," Journal of Medical Entomology, vol. 49, no. 3, pp. 563-572, 2012.

[42] H. Kato, R. C. Jochim, E. A. Gomez et al., "A repertoire of the dominant transcripts from the salivary glands of the bloodsucking bug, Triatoma dimidiata, a vector of Chagas disease," Infection, Genetics and Evolution, vol. 10, no. 2, pp. 184-191, 2010.

[43] T. C. F. Assumpção, S. Charneau, P. B. M. Santiago et al., "Insight into the salivary transcriptome and proteome of Dipetalogaster maxima," Journal of Proteome Research, vol. 10, no. 2, pp. 669-679, 2011.

[44] A. C. M. Bussacos, E. S. Nakayasu, M. M. Hecht et al., "Redundancy of proteins in the salivary glands of Panstrongylus megistus secures prolonged procurement for blood meals," Journal of Proteomics, vol. 74, no. 9, pp. 1693-1700, 2011.

[45] I. M. B. Francischetti, E. Calvo, J. F. Andersen et al., "Insight into the sialome of the bed bug, Cimex lectularius," Journal of Proteome Research, vol. 9, no. 8, pp. 3820-3831, 2010.

[46] I. M. B. Francischetti, A. H. Lopes, F. A. Dias, V. M. Pham, and J. M. C. Ribeiro, "An insight into the sialotranscriptome of the seed-feeding bug, oncopeltus fasciatus," Insect Biochemistry and Molecular Biology, vol. 37, no. 9, pp. 903-910, 2007.

[47] R. H. Cobben et al., "On the original feeding habits of the hemiptera (Insecta): a reply to Merrill Sweet," Annals of the Entomological Society of America, vol. 72, no. 6, pp. 711-715, 1979.

[48] V. Hypša, D. F. Tietz, J. Zrzavý, R. O. M. Rego, C. Galvao, and J. Jurberg, "Phylogeny and biogeography of triatominae (Hemiptera: Reduviidae): molecular evidence of a New world origin of the asiatic clade," Molecular Phylogenetics and Evolution, vol. 23, no. 3, pp. 447-457, 2002.

[49] C. J. Schofield and C. Galvão, "Classification, evolution, and species groups within the triatominae," Acta Tropica, vol. 110, no. 2-3, pp. 88-100, 2009.

[50] J. G. Valenzuela, O. M. Chuffe, and J. M. C. Ribeiro, "Apyrase and anti-platelet activities from the salivary glands of the bed bug Cimex lectularius," Insect Biochemistry and Molecular Biology, vol. 26, no. 6, pp. 557-562, 1996.

[51] E. Faudry, P. S. Rocha, T. Vernet, S. P. Lozzi, and A. R. L. Teixeira, "Kinetics of expression of the salivary apyrases in Triatoma infestans," Insect Biochemistry and Molecular Biology, vol. 34, no. 10, pp. 1051-1058, 2004.

[52] W. R. Montfort, A. Weichsel, and J. F. Andersen, "Nitrophorins and related antihemostatic lipocalins from Rhodnius prolixus and other blood-sucking arthropods," Biochimica et Biophysica Acta, vol. 1482, no. 1-2, pp. 110-118, 2000.

[53] J. F. Andersen, D. E. Champagne, A. Weichsel et al., "Nitric oxide binding and crystallization of recombinant nitrophorin $\mathrm{I}$, a nitric oxide transport protein from the blood-sucking bug Rhodnius prolixus," Biochemistry, vol. 36, no. 15, pp. 44234428, 1997. 
[54] A. Weichsel, J. F. Andersen, D. E. Champagne, F. A. Walker, and W. R. Montfort, "Crystal structures of a nitric oxide transport protein from a blood-sucking insect," Nature Structural Biology, vol. 5, no. 4, pp. 304-309, 1998.

[55] J. F. Andersen, A. Weichsel, C. A. Balfour, D. E. Champagne, and W. R. Montfort, "The crystal structure of nitrophorin 4 at $1.5 \AA$ resolution: transport of nitric oxide by a lipocalinbased heme protein," Structure, vol. 6, no. 10, pp. 1315-1327, 1998.

[56] I. M. B. Francischetti, A. Sá-Nunes, B. J. Mans, I. M. Santos, and J. M. C. Ribeiro, "The role of saliva in tick feeding," Frontiers in Bioscience, vol. 14, no. 6, pp. 2051-2088, 2009.

[57] I. M. B. Francischetti, "Platelet aggregation inhibitors from hematophagous animals," Toxicon, vol. 56, no. 7, pp. 11301144, 2010.

[58] J. W. Cornwall and W. S. Patton, "Some observations on the salivary secretion of the common blood-sucking insects and ticks," Indian Journal of Medical Research, vol. 2, pp. 569-593, 1914.

[59] J. M. C. Ribeiro and E. S. Garcia, "Platelet antiaggregating activity in the salivary secretion of the blood sucking bug Rhodnius prolixus," Experientia, vol. 37, no. 4, pp. 384-386, 1981.

[60] M. J. Mant and K. R. Parker, "Two platelet aggregation inhibitors in tsetse (Glossina) saliva with studies of roles of thrombine and citrate in in vitro platelet aggregation," British Journal of Haematology, vol. 48, no. 4, pp. 601-608, 1981.

[61] J. M. C. Ribeiro, A. Vachereau, G. B. Modi, and R. B. Tesh, "A novel vasodilatory peptide from the salivary glands of the sand fly Lutzomyia longipalpis," Science, vol. 243, no. 4888, pp. 212-214, 1989.

[62] K. Hellmann and R. I. Hawkins, "Prolixin-S and Prolixin-G; two anticoagulants from Rhodnius prolixus Stål," Nature, vol. 207, no. 4994, pp. 265-267, 1965.

[63] J. J. B. Smith, R. A. Cornish, and J. Wilkes, "Properties of a calcium-dependent apyrase in the saliva of the blood-feeding bug, Rhodnius prolixus," Experientia, vol. 36, no. 8, pp. 898900, 1980.

[64] J. M. C. Ribeiro, R. Gonzales, and O. Marinotti, "A salivary vasodilator in the blood-sucking bug, Rhodnius prolixus," British Journal of Pharmacology, vol. 101, no. 4, pp. 932-936, 1990.

[65] R. R. Cavalcante, M. H. Pereira, and N. F. Gontijo, "Anticomplement activity in the saliva of phlebotomine sand flies and other haematophagous insects," Parasitology, vol. 127, no. 1, pp. 87-93, 2003.

[66] J. M. C. Ribeiro, "The antiserotonin and antihistamine activities of salivary secretion of Rhodnius prolixus," Journal of Insect Physiology, vol. 28, no. 1, pp. 69-75, 1982.

[67] J. M. C. Ribeiro and J. J. F. Sarkis, "Anti-thromboxane activity in Rhodnius prolixus salivary secretion," Journal of Insect Physiology, vol. 28, no. 8, pp. 655-660, 1982.

[68] Á. Dan, M. H. Pereira, J. L. Pesquero, L. Diotaiuti, and P. S. Lacerda Beirão, "Action of the saliva of Triatoma infestans (Heteroptera: Reduviidae) on sodium channels," Journal of Medical Entomology, vol. 36, no. 6, pp. 875-879, 1999.

[69] S. F. Altschul, T. L. Madden, A. A. Schäffer et al., "Gapped BLAST and PSI-BLAST: a new generation of protein database search programs," Nucleic Acids Research, vol. 25, no. 17, pp. 3389-3402, 1997.

[70] M. Ashburner, C. A. Ball, J. A. Blake et al., "Gene ontology: tool for the unification of biology," Nature Genetics, vol. 25, no. 1, pp. 25-29, 2000.
[71] D. L. Wheeler, T. Barrett, D. A. Benson et al., "Database resources of the National Center for Biotechnology Information," Nucleic Acids Research, vol. 33, pp. D39-D45, 2005.

[72] A. Marchler-Bauer, A. R. Panchenko, B. A. Shoemarker, P. A. Thiessen, L. Y. Geer, and S. H. Bryant, "CDD: a database of conserved domain alignments with links to domain threedimensional structure," Nucleic Acids Research, vol. 30, no. 1, pp. 281-283, 2002.

[73] H. Nielsen, S. Brunak, and G. von Heijne, "Machine learning approaches for the prediction of signal peptides and other protein sorting signals," Protein Engineering, vol. 12, no. 1, pp. 3-9, 1999.

[74] E. L. Sonnhammer, G. von Heijne, and A. Krogh, "A hidden Markov model for predicting transmembrane helices in protein sequences," Proceedings International Conference on Intelligent Systems for Molecular Biology, vol. 6, pp. 175-182, 1998.

[75] J. E. Hansen, O. Lund, N. Tolstrup, A. A. Gooley, K. L. Williams, and S. Brunak, "NetOglyc: prediction of mucin type O-glycosylation sites based on sequence context and surface accessibility," Glycoconjugate Journal, vol. 15, no. 2, pp. 115-130, 1998.

[76] "Heteroptera: true bugs," http://tolweb.org/Heteroptera/ 10805/2009.02.27.

[77] H. M. Kalckar, "Adenylpyrophosphatase and myokinase," The Journal of Biological Chemistry, vol. 153, pp. 355-373, 1945.

[78] O. Meyerhoff et al., "The origin of the reaction of Harden and Young in cell-free alcoholic fermentation," The Journal of Biological Chemistry, vol. 157, pp. 105-119, 1945.

[79] P. S. Krishnam, "Studies on apyrase. II: some properties of potato apyrase," Archives of Biochemistry, vol. 20, no. 2, pp. 272-283, 1949.

[80] K. H. Lee, J. Z. Ksezanoski, J. J. Eiler et al., "Mode of action of potato apyrase," Proceedings of the Society for Experimental Biology and Medicine, vol. 1, no. 94, pp. 193-195, 1957.

[81] X. D. Gao, V. Kaigorodov, and Y. Jigami, "YND1, a homologue of GDA1, encodes membrane-bound apyrase required for Golgi $\mathrm{N}$ - and O-glycosylation in Saccharomyces cerevisiae," The Journal of Biological Chemistry, vol. 274, no. 30, pp. 21450-21456, 1999.

[82] C. D’Alessio, E. S. Trombetta, and A. J. Parodi, "Nucleoside diphosphatase and glycosyltransferase activities can localize to different subcellular compartments in Schizosaccharomyces pombe," The Journal of Biological Chemistry, vol. 278, no. 25, pp. 22379-22387, 2003.

[83] J. J. Sarkis, J. A. Guimarães, and J. M. Ribeiro, "Salivary apyrase of Rhodnius prolixus. Kinetics and purification," Biochemical Journal, vol. 233, no. 3, pp. 885-891, 1986.

[84] J. M. C. Ribeiro and E. S. Garcia, "The salivary and crop apyrase activity of Rhodnius prolixus," Journal of Insect Physiology, vol. 26, no. 5, pp. 303-307, 1980.

[85] J. M. C. Ribeiro, J. J. F. Sarkis, P. A. Rossignol, and A. Spielman, "Salivary apyrase of Aedes aegypti: characterization and secretory fate," Comparative Biochemistry and Physiology $B$, vol. 79, no. 1, pp. 81-86, 1984.

[86] J. M. C. Ribeiro, P. A. Rossignol, and A. Spielman, "Salivary gland apyrase determines probing time in anopheline mosquitoes," Journal of Insect Physiology, vol. 31, no. 9, pp. 689-692, 1985.

[87] D. E. Champagne, C. T. Smartt, J. M. C. Ribeiro, and A. A. James, "The salivary gland-specific apyrase of the mosquito Aedes aegypti is a member of the 5'-nucleotidase family," Proceedings of the National Academy of Sciences of the United States of America, vol. 92, no. 3, pp. 694-698, 1995. 
[88] J. Schulte Am Esch, J. Sévigny, E. Kaczmarek et al., "Structural elements and limited proteolysis of CD39 influence ATP diphosphohydrolase activity," Biochemistry, vol. 38, no. 8, pp. 2248-2258, 1999.

[89] K. T. Tan, S. P. Watson, and G. Y. H. Lip, “The endothelium and platelets in cardiovascular disease: potential targets for therapeutic intervention," Current Medicinal Chemistry, vol. 2, no. 2, pp. 169-178, 2004.

[90] A. J. Marcus, M. J. Broekman, J. H. F. Drosopoulos et al., "Role of CD39 (NTPDase-1) in thromboregulation, cerebroprotection, and cardioprotection," Seminars in Thrombosis and Hemostasis, vol. 31, no. 2, pp. 234-246, 2005.

[91] B. U. Failer, N. Braun, and H. Zimmermann, "Cloning, expression, and functional characterization of a $\mathrm{Ca}^{2+}$ dependent endoplasmic reticulum nucleoside diphosphatase," The Journal of Biological Chemistry, vol. 277, no. 40, pp. 36978-36986, 2002.

[92] C. Devader, R. J. Webb, G. M. H. Thomas, and L. Dale, "Xenopus apyrase (xapy), a secreted nucleotidase that is expressed during early development," Gene, vol. 367 , no. 12, pp. 135-141, 2006.

[93] J. G. Valenzuela, Y. Belkaid, E. Rowton, and J. M. C. Ribeiro, "The salivary apyrase of the blood-sucking sand fly Phlebotomus papatasi belongs to the novel Cimex family of apyrases," Journal of Experimental Biology, vol. 204, no. 2, pp. 229-237, 2001.

[94] D. Sun, A. Mcnicol, A. A. James, and Z. Peng, "Expression of functional recombinant mosquito salivary apyrase: a potential therapeutic platelet aggregation inhibitor," Platelets, vol. 17, no. 3, pp. 178-184, 2006.

[95] M. Andersson, "Diadenosine tetraphosphate (Ap4A): its presence and functions in biological systems," International Journal of Biochemistry, vol. 21, no. 7, pp. 707-714, 1989.

[96] H. Schlüter, M. Tepel, and W. Zidek, "Vascular actions of diadenosine phosphates," Journal of Autonomic Pharmacology, vol. 16, no. 6, pp. 357-362, 1996.

[97] L. L. Kisselev, J. Justesen, A. D. Wolfson, and L. Y. Frolova, "Diadenosine oligophosphates $(\mathrm{AP}(\mathrm{n}) \mathrm{A})$, a novel class of signalling molecules?” FEBS Letters, vol. 427, no. 2, pp. 157$163,1998$.

[98] B. M. Stavrou, "Diadenosine polyphosphates: postulated mechanisms mediating the cardiac effects," Current Medicinal Chemistry, vol. 1, no. 2, pp. 151-169, 2003.

[99] E. Calvo and J. M. C. Ribeiro, "A novel secreted endonuclease from Culex quinquefasciatus salivary glands," Journal of Experimental Biology, vol. 209, no. 14, pp. 2651-2659, 2006.

[100] J. G. Valenzuela, M. Garfield, E. D. Rowton, and V. M. Pham, "Identification of the most abundant secreted proteins from the salivary glands of the sand fly Lutzomyia longipalpis, vector of Leishmania chagasi," Journal of Experimental Biology, vol. 207, no. 21, pp. 3717-3729, 2004.

[101] J. M. Anderson, F. Oliveira, S. Kamhawi et al., "Comparative salivary gland transcriptomics of sandfly vectors of visceral leishmaniasis," BMC Genomics, vol. 7, article 52, 2006.

[102] J. M. C. Ribeiro, R. Charlab, and J. G. Valenzuela, "The salivary adenosine deaminase activity of the mosquitoes Culex quinquefasciatus and Aedes aegypti," Journal of Experimental Biology, vol. 204, no. 11, pp. 2001-2010, 2001.

[103] R. Charlab, E. D. Rowton, and J. M. C. Ribeiro, "The salivary adenosine deaminase from the sand fly Lutzomyia longipalpis," Experimental Parasitology, vol. 95, no. 1, pp. 45$53,2000$.

[104] H. Kato, R. C. Jochim, P. G. Lawyer, and J. G. Valenzuela, "Identification and characterization of a salivary adenosine deaminase from the sand fly Phlebotomus duboscqi, the vector of Leishmania major in sub-Saharan Africa," Journal of Experimental Biology, vol. 210, no. 5, pp. 733-740, 2007.

[105] S. J. Harris, R. V. Parry, J. Westwick, and S. G. Ward, "Phosphoinositide lipid phosphatases: natural regulators of phosphoinositide 3-kinase signaling in T lymphocytes," The Journal of Biological Chemistry, vol. 283, no. 5, pp. 24652469, 2008.

[106] S. P. Watson, B. Reep, R. T. McConnell, and E. G. Lapetina, "Collagen stimulates $[3 \mathrm{H}]$ inositol triphosphate formation in indomethacin-treated human platelets," Biochemical Journal, vol. 226, no. 3, pp. 831-837, 1985.

[107] R. Amino, A. S. Tanaka, and S. Schenkman, "Triapsin, an unusual activatable serine protease from the saliva of the hematophagous vector of Chagas' disease Triatoma infestans (Hemiptera: Reduviidae)," Insect Biochemistry and Molecular Biology, vol. 31, no. 4-5, pp. 465-472, 2001.

[108] G. Colebatch, P. Cooper, and P. East, "cDNA cloning of a salivary chymotrypsin-like protease and the identification of six additional cDNAs encoding putative digestive proteases from the green mirid, Creontiades dilutus (Hemiptera: Miridae)," Insect Biochemistry and Molecular Biology, vol. 32, no. 9, pp. 1065-1075, 2002.

[109] Y. C. Zhu, F. Zeng, and B. Oppert, "Molecular cloning of trypsin-like cDNAs and comparison of proteinase activities in the salivary glands and gut of the tarnished plant bug Lygus lineolaris (Heteroptera: Miridae)," Insect Biochemistry and Molecular Biology, vol. 33, no. 9, pp. 889-899, 2003.

[110] F. Zeng, Y. C. Zhu, and A. C. Cohen, "Molecular cloning and partial characterization of a trypsin-like protein in salivary glands of Lygus hesperus (hemiptera: Miridae)," Insect Biochemistry and Molecular Biology, vol. 32, no. 4, pp. 455-464, 2002.

[111] I. M. B. Francischetti, T. N. Mather, and J. M. C. Ribeiro, "Cloning of a salivary gland metalloprotease and characterization of gelatinase and fibrin(ogen)lytic activities in the saliva of the Lyme disease tick vector Ixodes scapularis," Biochemical and Biophysical Research Communications, vol. 305, no. 4, pp. 869-875, 2003.

[112] I. M. B. Francischetti, T. N. Mather, and J. M. C. Ribeiro, "Tick saliva is a potent inhibitor of endothelial cell proliferation and angiogenesis," Thrombosis and Haemostasis, vol. 94, no. 1, pp. 167-174, 2005.

[113] M. P. Williamson, D. Marion, and K. Wüthrich, "Secondary structure in the solution conformation of the proteinase inhibitor IIA from bull seminal plasma by nuclear magnetic resonance," Journal of Molecular Biology, vol. 173, no. 3, pp. 341-359, 1984.

[114] I. T. N. Campos, R. Amino, C. A. M. Sampaio et al., "Infestin, a thrombin inhibitor presents in Triatoma infestans midgut, a Chagas' disease vector: gene cloning, expression and characterization of the inhibitor," Insect Biochemistry and Molecular Biology, vol. 32, no. 9, pp. 991-997, 2002.

[115] D. V. Lovato, I. T. Nicolau de Campos, R. Amino, and A. S. Tanaka, "The full-length cDNA of anticoagulant protein infestin revealed a novel releasable Kazal domain, a neutrophil elastase inhibitor lacking anticoagulant activity," Biochimie, vol. 88, no. 6, pp. 673-681, 2006.

[116] T. Friedrich, B. Kroger, S. Bialojan et al., "A Kazal-type inhibitor with thrombin specificity from Rhodnius prolixus," The Journal of Biological Chemistry, vol. 268, no. 22, pp. 16216-16222, 1993.

[117] K. Mende, O. Petoukhova, V. Koulitchkova et al., "Dipetalogastin, a potent thrombin inhibitor from the blood-sucking 
insect Dipetalogaster maximus. cDNA cloning, expression and characterization," European Journal of Biochemistry, vol. 266, no. 2, pp. 583-590, 1999.

[118] H. Isawa, M. Yuda, K. Yoneda, and Y. Chinzei, "The insect salivary protein, prolixin-S, inhibits factor IXa generation and Xase complex formation in the blood coagulation pathway," The Journal of Biological Chemistry, vol. 275, no. 9, pp. 6636-6641, 2000.

[119] H. J. Mägert, L. Ständker, P. Kreutzmann et al., "LEKTI, a novel 15-domain type of human serine proteinase inhibitor," The Journal of Biological Chemistry, vol. 274, no. 31, pp. 21499-21502, 1999.

[120] R. Augustin, S. Siebert, and T. C. G. Bosch, "Identification of a kazal-type serine protease inhibitor with potent antistaphylococcal activity as part of Hydra's innate immune system," Developmental and Comparative Immunology, vol. 33, no. 7, pp. 830-837, 2009.

[121] P. Takáč, M. A. Nunn, J. Mészáros et al., "Vasotab, a vasoactive peptide from horse fly Hybomitra bimaculata (Diptera, Tabanidae) salivary glands," Journal of Experimental Biology, vol. 209, no. 2, pp. 343-352, 2006.

[122] M. R. Kanost, "Serine proteinase inhibitors in arthropod immunity," Developmental and Comparative Immunology, vol. 23, no. 4-5, pp. 291-301, 1999.

[123] J. C. Rau, L. M. Beaulieu, J. A. Huntington, and F. C. Church, "Serpins in thrombosis, hemostasis and fibrinolysis," Journal of Thrombosis and Haemostasis, vol. 5, no. 1, pp. 102-115, 2007.

[124] K. R. Stark and A. A. James, "Isolation and characterization of the gene encoding a novel factor Xa-directed anticoagulant from the yellow fever mosquito, Aedes aegypti," The Journal of Biological Chemistry, vol. 273, no. 33, pp. 20802-20809, 1998.

[125] E. Calvo, D. M. Mizurini, A Sá-Nunes et al., "Alboserpin, a factor Xa inhibitor from the mosquito vector of yellow fever, binds heparin and membrane phospholipids and exhibits antithrombotic activity," The Journal of Biological Chemistry, vol. 286, no. 32, pp. 27998-28010, 2011.

[126] C. Kellenberger and A. Roussel, "Structure-activity relationship within the serine protease inhibitors of the Pacifastin family," Protein and Peptide Letters, vol. 12, no. 5, pp. 409414, 2005.

[127] M. Abrahamson, M. Alvarez-Fernandez, and C. M. Nathanson, "Cystatins," Biochemical Society Symposium, no. 70, pp. 179-199, 2003.

[128] M. Solomon, B. Belenghi, M. Delledonne, E. Menachem, and A. Levine, "The involvement of cysteine proteases and protease inhibitor genes in the regulation of programmed cell death in plants," Plant Cell, vol. 11, no. 3, pp. 431-443, 1999.

[129] M. Estelle, "Proteases and cellular regulation in plants," Current Opinion in Plant Biology, vol. 4, no. 3, pp. 254-260, 2001.

[130] M. Kotsyfakis, A. Sá-Nunes, I. M. B. Francischetti, T. N. Mather, J. F. Andersen, and J. M. C. Ribeiro, "Antiinflammatory and immunosuppressive activity of sialostatin L, a salivary cystatin from the tick Ixodes scapularis," The Journal of Biological Chemistry, vol. 281, no. 36, pp. 26298-26307, 2006.

[131] D. R. Flower, A. C. T. North, and C. E. Sansom, "The lipocalin protein family: structural and sequence overview," Biochimica et Biophysica Acta, vol. 1482, no. 1-2, pp. 9-24, 2000.

[132] J. F. Andersen, N. P. Gudderra, I. M. B. Francischetti, and J. M. C. Ribeiro, "The role of salivary lipocalins in blood feeding by Rhodnius prolixus," Archives of Insect Biochemistry and Physiology, vol. 58, no. 2, pp. 97-105, 2005.
[133] S. Schlehuber and A. Skerra, "Lipocalins in drug discovery: from natural ligand-binding proteins to 'anticalins,", Drug Discovery Today, vol. 10, no. 1, pp. 23-33, 2005.

[134] S. Ohno, Evolution by Gene Duplication, Springer, Berlin, Germany, 1970.

[135] E. V. Koonin, "Orthologs, paralogs, and evolutionary genomics," Annual Review of Genetics, vol. 39, pp. 309-338, 2005.

[136] B. J. Mans, A. I. Louw, and A. W. H. Neitz, "Evolution of hematophagy in ticks: common-origins for blood coagulation and platelet aggregation inhibitors from soft ticks of the genus Ornithodoros," Molecular Biology and Evolution, vol. 19, no. 10, pp. 1695-1705, 2002.

[137] M. Hurles, "Gene duplication: the genomic trade in spare parts," PLos Biology, vol. 2, no. 7, Article ID E206, 2004.

[138] J. M. C. Ribeiro, B. J. Mans, and B. Arcà, "An insight into the sialome of blood-feeding Nematocera," Insect Biochemistry and Molecular Biology, vol. 40, no. 11, pp. 767-784, 2010.

[139] B. G. Fry, K. Roelants, D. E. Champagne et al., "The toxicogenomic multiverse: convergent recruitment of proteins into animal venoms," Annual Review of Genomics and Human Genetics, vol. 10, pp. 483-511, 2009.

[140] J. M. C Ribeiro and B. Arca, "From sialomes to the sialoverse: an insight into the salivary potion of blood feeding insects," Advances in Insect Physiology, vol. 37, pp. 59-118, 2009.

[141] Y. Zhang, J. M. C. Ribeiro, J. A. Guimarães, and P. N. Walsh, "Nitrophorin-2: a novel mixed-type reversible specific inhibitor of the intrinsic factor-X activating complex," Biochemistry, vol. 37, no. 30, pp. 10681-10690, 1998.

[142] B. J. Mans and J. M. C. Ribeiro, "Function, mechanism and evolution of the moubatin-clade of soft tick lipocalins," Insect Biochemistry and Molecular Biology, vol. 38, no. 9, pp. 841852, 2008.

[143] B. J. Mans and J. M. C. Ribeiro, "A novel clade of cysteinyl leukotriene scavengers in soft ticks," Insect Biochemistry and Molecular Biology, vol. 38, no. 9, pp. 862-870, 2008.

[144] B. J. Mans, J. M. C. Ribeiro, and J. F. Andersen, "Structure, function, and evolution of biogenic amine-binding proteins in soft ticks," The Journal of Biological Chemistry, vol. 283, no. 27, pp. 18721-18733, 2008.

[145] S. Sangamnatdej, G. C. Paesen, M. Slovak, and P. A. Nuttall, "A high affinity serotonin- and histamine-binding lipocalin from tick saliva," Insect Molecular Biology, vol. 11, no. 1, pp. 79-86, 2002.

[146] G. C. Paesen, P. L. Adams, P. A. Nuttall, and D. L. Stuart, "Tick histamine-binding proteins: lipocalins with a second binding cavity," Biochimica et Biophysica Acta, vol. 1482, no. 1-2, pp. 92-101, 2000.

[147] G. C. Paesen, P. L. Adams, K. Harlos, P. A. Nuttall, and D. I. Stuart, "Tick histamine-binding proteins: isolation, cloning, and three-dimensional structure," Molecular Cell, vol. 3, no. 5, pp. 661-671, 1999.

[148] M. A. Nunn, A. Sharma, G. C. Paesen et al., "Complement inhibitor of C5 activation from the soft tick Ornithodoros moubata," Journal of Immunology, vol. 174, no. 4, pp. 20842091, 2005.

[149] V. B. Wigglesworth et al., "The fate of haemoglobin in Rhodnius prolixus (Hemiptera) and other blood-sucking arthropods," Proceedings of the Royal Society B, vol. 131, pp. 313-339, 1942.

[150] J. M. C. Ribeiro, M. Schneider, T. Isaias, J. Jurberg, C. Galvão, and J. A. Guimarães, "Role of salivary antihemostatic components in blood feeding by triatomine bugs (Heteroptera)," Journal of Medical Entomology, vol. 35, no. 4, pp. 599-610, 1998. 
[151] K. Galindo and D. P. Smith, "A large family of divergent Drosophila odorant-binding proteins expressed in gustatory and olfactory sensilla," Genetics, vol. 159, no. 3, pp. 10591072, 2001.

[152] D. S. Hekmat-Scafe, R. L. Dorit, and J. R. Carlson, "Molecular evolution of odorant-binding protein genes OS-E and OS-F in Drosophila," Genetics, vol. 155, no. 1, pp. 117-127, 2000.

[153] E. Calvo, B. J. Mans, J. M. C. Ribeiro, and J. F. Andersen, "Multifunctionality and mechanism of ligand binding in a mosquito antiinflammatory protein," Proceedings of the National Academy of Sciences of the United States of America, vol. 106, no. 10, pp. 3728-3733, 2009.

[154] B. J. Mans, E. Calvo, J. M. C. Ribeiro, and J. F. Andersen, "The crystal structure of D7r4, a salivary biogenic amine-binding protein from the malaria mosquito Anopheles gambiae," The Journal of Biological Chemistry, vol. 282, no. 50, pp. 3662636633, 2007.

[155] E. Calvo, B. J. Mans, J. F. Andersen, and J. M. C. Ribeiro, "Function and evolution of a mosquito salivary protein family," The Journal of Biological Chemistry, vol. 281, no. 4, pp. 1935-1942, 2006.

[156] H. Isawa, M. Yuda, Y. Orito, and Y. Chinzei, "A mosquito salivary protein inhibits activation of the plasma contact system by binding to factor XII and high molecular weight kininogen," The Journal of Biological Chemistry, vol. 277, no. 31, pp. 27651-27658, 2002.

[157] G. M. Gibbs, K. Roelants, and M. K. O’Bryan, “The CAP superfamily: cysteine-rich secretory proteins, antigen 5 , and pathogenesis-related 1 proteins-roles in reproduction, cancer, and immune defense," Endocrine Reviews, vol. 29, no. 7, pp. 865-897, 2008.

[158] Y. Yamazaki and T. Morita, "Structure and function of snake venom cysteine-rich secretory proteins," Toxicon, vol. 44, no. 3, pp. 227-231, 2004.

[159] Y. Yamazaki, H. Koike, Y. Sugiyama et al., "Cloning and characterization of novel snake venom proteins that block smooth muscle contraction," European Journal of Biochemistry, vol. 269, no. 11, pp. 2708-2715, 2002.

[160] M. Nobile, F. Noceti, G. Prestipino, and L. D. Possani, "Helothermine, a lizard venom toxin, inhibits calcium current in cerebellar granules," Experimental Brain Research, vol. 110, no. 1, pp. 15-20, 1996.

[161] M. Ameri, X. Wang, M. J. Wilkerson, M. R. Kanost, and A. B. Broce, "An immunoglobulin binding protein (antigen 5) of the stable fly (diptera: Muscidae) salivary gland stimulates bovine immune responses," Journal of Medical Entomology, vol. 45 , no. 1, pp. 94-101, 2008.

[162] D. Ma, X. Xu, S. An et al., "A novel family of RGDcontaining disintegrins (Tablysin-15) from the salivary gland of the horsefly tabanus yao targets $\alpha \operatorname{IIb} \beta 3$ or $\alpha \mathrm{V} \beta 3$ and inhibits platelet aggregation and angiogenesis," Thrombosis and Haemostasis, vol. 105, no. 6, pp. 1032-1045, 2011.

[163] D. Ma, Y. Wang, H. Yang et al., "Anti-thrombosis repertoire of blood-feeding horsefly salivary glands," Molecular and Cellular Proteomics, vol. 8, no. 9, pp. 2071-2079, 2009.

[164] X. Xu, H. Yang, D. Ma et al., "Toward an understanding of the molecular mechanism for successful blood feeding by coupling proteomics analysis with pharmacological testing of horsefly salivary glands," Molecular and Cellular Proteomics, vol. 7, no. 3, pp. 582-590, 2008.

[165] D. C. de Graaf, M. Aerts, M. Brunain et al., "Insights into the venom composition of the ectoparasitoid wasp Nasonia vitripennis from bioinformatic and proteomic studies," Insect Molecular Biology, vol. 19, no. 1, pp. 11-26, 2010.
[166] J. Alves-Silva, J. M. C. Ribeiro, J. van den Abbeele et al., "An insight into the sialome of Glossina morsitans morsitans," BMC Genomics, vol. 11, no. 1, article 213, 2010.

[167] D. R. Maddison, K. S. Schulz, and W. P. Maddison, "The tree of life web project," Zootaxa, no. 1668, pp. 19-40, 2007.

[168] C. Galvão, J. S. Patterson, D. Da Silva Rocha et al., "A new species of Triatominae from Tamil Nadu, India," Medical and Veterinary Entomology, vol. 16, no. 1, pp. 75-82, 2002. 

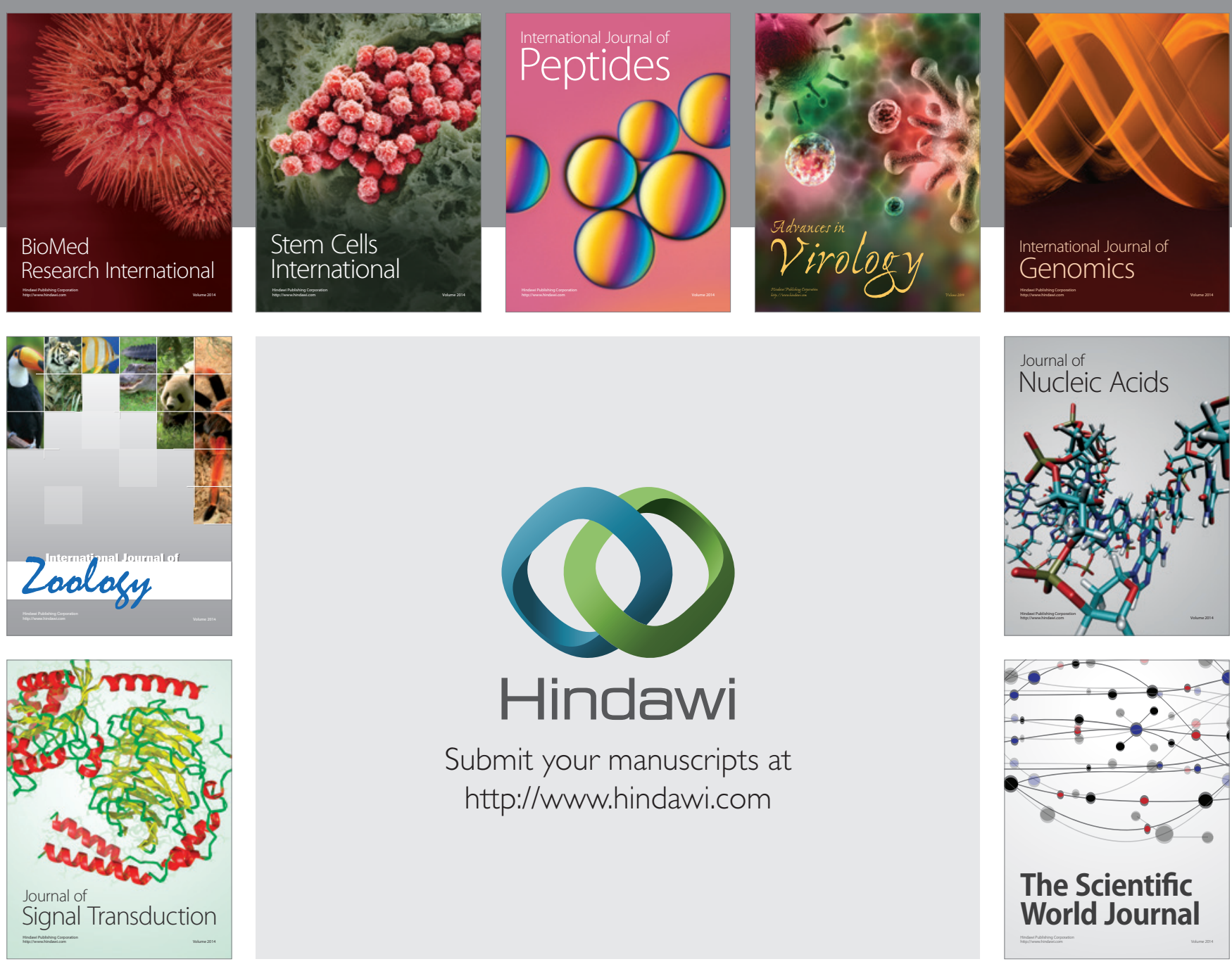

Submit your manuscripts at

http://www.hindawi.com


The Scientific World Journal
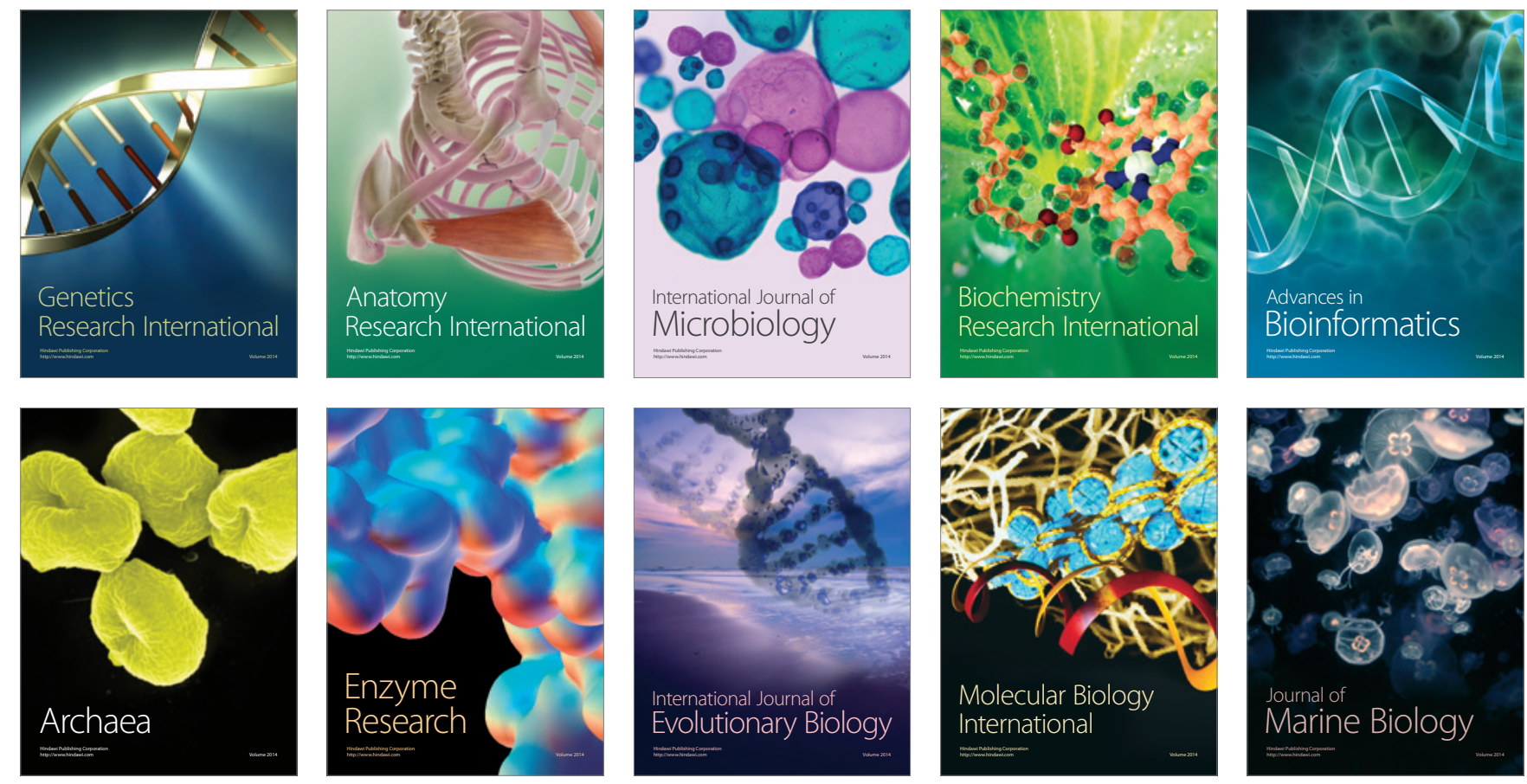